\title{
The effects of height and BMI on prostate cancer incidence and mortality: a Mendelian randomization study in 20,848 cases and 20,214 controls from the PRACTICAL consortium
}

\author{
Neil M. Davies ${ }^{1,2} \cdot$ Tom R. Gaunt ${ }^{1,2} \cdot$ Sarah J. Lewis ${ }^{1,2} \cdot$ Jeff Holly $^{3} \cdot$ Jenny L. Donovan $^{1}$ • \\ Freddie C. Hamdy ${ }^{4} \cdot$ John P. Kemp $^{2,5} \cdot$ Rosalind Eeles $^{6,7} \cdot$ Doug Easton $^{8} \cdot$ Zsofia Kote-Jarai $^{6}$. \\ Ali Amin Al Olama ${ }^{8} \cdot$ Sara Benlloch $^{8} \cdot$ Kenneth Muir $^{9} \cdot$ Graham G. Giles $^{10,11} \cdot$ Fredrik Wiklund $^{12}$. \\ Henrik Gronberg ${ }^{12}$ - Christopher A. Haiman ${ }^{13}$ • Johanna Schleutker ${ }^{14,15}$ • Børge G. Nordestgaard ${ }^{16}$. \\ Ruth C. Travis ${ }^{17}$ - David Neal ${ }^{18,19}$ • Nora Pashayan ${ }^{20,41}$ - Kay-Tee Khaw ${ }^{21}$ - Janet L. Stanford ${ }^{22,23}$. \\ William J. Blot $^{24} \cdot$ Stephen Thibodeau $^{25}$ - Christiane Maier ${ }^{26,27}$ - Adam S. Kibel ${ }^{28,29}$ - Cezary Cybulski $^{30}$. \\ Lisa Cannon-Albright ${ }^{31} \cdot$ Hermann Brenner $^{32,33,34} \cdot$ Jong Park $^{35} \cdot$ Radka Kaneva $^{36} \cdot$ Jyotsna $^{3}$ Batra $^{37}$. \\ Manuel R. Teixeira ${ }^{38,39} \cdot$ Hardev Pandha ${ }^{40} \cdot$ PRACTICAL consortium • Mark Lathrop ${ }^{42,43} \cdot$ \\ George Davey Smith ${ }^{1,2} \cdot$ Richard M. Martin ${ }^{1,2,44}$
}

Received: 9 April 2015/Accepted: 12 August 2015/Published online: 19 September 2015

(C) The Author(s) 2015. This article is published with open access at Springerlink.com

\begin{abstract}
Background Epidemiological studies suggest a potential role for obesity and determinants of adult stature in prostate cancer risk and mortality, but the relationships described in the literature are complex. To address uncertainty over the causal nature of previous observational findings, we investigated associations of height- and adiposity-related genetic variants with prostate cancer risk and mortality.
\end{abstract}

PRACTICAL consortium is provided in appendix section.

Electronic supplementary material The online version of this article (doi:10.1007/s10552-015-0654-9) contains supplementary material, which is available to authorized users.

Richard M. Martin

richard.martin@bristol.ac.uk

Neil M. Davies

neil.davies@bristol.ac.uk

1 School of Social and Community Medicine, University of Bristol, Bristol, UK

2 MRC Integrative Epidemiology Unit, University of Bristol, Bristol, UK

3 School of Clinical Sciences, University of Bristol, Bristol BS10 5NB, UK

4 Nuffield Department of Surgery, University of Oxford, Oxford, UK

5 University of Queensland Diamantina Institute, Translational Research Institute, Brisbane, QLD, Australia
Methods We conducted a case-control study based on 20,848 prostate cancers and 20,214 controls of European ancestry from 22 studies in the PRACTICAL consortium. We constructed genetic risk scores that summed each man's number of height and BMI increasing alleles across multiple single nucleotide polymorphisms robustly associated with each phenotype from published genome-wide association studies.

Results The genetic risk scores explained 6.31 and $1.46 \%$ of the variability in height and BMI, respectively. There was only weak evidence that genetic variants previously associated with increased BMI were associated with a lower prostate cancer risk (odds ratio per standard deviation

The Institute of Cancer Research, London SM2 5NG, UK

7 The Royal Marsden NHS Foundation Trust, London SW3 6JJ, UK

8 Strangeways Laboratory, Centre for Cancer Genetic Epidemiology, Department of Public Health and Primary Care, University of Cambridge, Worts Causeway, Cambridge, UK

9 Institute of Population Health, University of Manchester, Manchester, UK

10 Cancer Epidemiology Centre, The Cancer Council Victoria, 615 St Kilda Road, Melbourne, VIC, Australia

11 Centre for Epidemiology and Biostatistics, Melbourne School of Population and Global Health, The University of Melbourne, Melbourne, VIC, Australia 
increase in BMI genetic score 0.98; $95 \%$ CI 0.96, 1.00; $p=0.07)$. Genetic variants associated with increased height were not associated with prostate cancer incidence (OR 0.99; $95 \%$ CI $0.97,1.01 ; p=0.23$ ), but were associated with an increase (OR 1.13; $95 \%$ CI 1.08, 1.20) in prostate cancer mortality among low-grade disease ( $p$ heterogeneity, low vs. high grade $<0.001)$. Genetic variants associated with increased BMI were associated with an increase (OR 1.08; $95 \%$ CI $1.03,1.14)$ in all-cause mortality among men with low-grade disease ( $p$ heterogeneity $=0.03$ ).

Conclusions We found little evidence of a substantial effect of genetically elevated height or BMI on prostate cancer risk, suggesting that previously reported observational associations may reflect common environmental determinants of height or BMI and prostate cancer risk. Genetically elevated height and BMI were associated with increased mortality (prostate cancer-specific and all-cause, respectively) in men with low-grade disease, a potentially informative but novel finding that requires replication.

Keywords Height - Body mass index - Prostate cancer . Mendelian randomization - Single nucleotide polymorphisms $\cdot$ Instrumental variables analysis

\section{Introduction}

Prostate cancer is the most common male cancer in Europe and North America, but the robust identification of potentially modifiable risk factors has proven elusive [1]. Epidemiological studies suggest a potential role for obesity [2-5] and determinants of adult stature [6], but the

12 Department of Medical Epidemiology and Biostatistics, Karolinska Institute, Stockholm, Sweden

13 Department of Preventive Medicine, Keck School of Medicine, University of Southern California/Norris Comprehensive Cancer Center, Los Angeles, CA, USA

14 Department of Medical Biochemistry and Genetics, University of Turku, Turku, Finland

15 Institute of Biomedical Technology/BioMediTech, University of Tampere and FimLab Laboratories, Tampere, Finland

16 Department of Clinical Biochemistry, Herlev Hospital, Copenhagen University Hospital, Herlev Ringvej 75, 2730 Herlev, Denmark

17 Cancer Epidemiology Unit, Nuffield Department of Clinical Medicine, University of Oxford, Oxford, UK

18 Surgical Oncology (Uro-Oncology: S4), University of Cambridge, Addenbrooke's Hospital, Hills Road, Box 279, Cambridge, UK

19 Li Ka Shing Centre, Cancer Research UK Cambridge Research Institute, Cambridge, UK relationships described in the literature are complex [7-9]. Inverse associations have generally been observed between adiposity and localized prostate cancer, but associations are largely positive with advanced or high-grade $[2,10]$ and fatal [3] cancer and may vary in direction depending on whether obesity was observed in early or middle to late adulthood [4]. Adult stature is generally positively associated with prostate cancer, although associations may be stronger for fatal [11] or high- compared with low-grade disease [6].

The explanation for these associations is unclear. Observations regarding obesity could be due to confounding by common causes of both obesity and prostate cancer (e.g., calorie and dietary fat intake) [12]; the mitogenic hormones insulin and insulin-like growth factor-I [13, 14]; delayed detection in obese men [8,9]; or a real biological effect [15]. Observed height associations could reflect early-life environmental (e.g., fetal, dietary, social, hormones, and psychological circumstances) or shared genetic contributions to stature and prostate cancer risk [16-18].

Genetic epidemiological studies are less susceptible to confounding than observational epidemiology. This is because conditional on population structure, genetic variants are more likely to be independent of later environment and lifestyle factors [19]; they are also unlikely to be affected by reverse causation. Thus, the existence of genetic variation in obesity and height can provide robust evidence about how associations of phenotypes, in this case obesity and height, with diseases arise [15]. We previously reported that a single nucleotide polymorphism (SNP) associated with obesity (FTO rs9939609-A) was inversely associated with lowgrade prostate cancer (odds ratio, OR 0.90 per A allele; $95 \%$ CI $0.81,0.99 ; p=0.03$ ), but positively associated with high-

20 Strangeways Laboratory, Centre for Cancer Genetic Epidemiology, Department of Oncology, University of Cambridge, Worts Causeway, Cambridge, UK

21 Cambridge Institute of Public Health, University of Cambridge, Forvie Site, Robinson Way,

Cambridge CB2 OSR, UK

22 Division of Public Health Sciences, Fred Hutchinson Cancer Research Center, Seattle, WA, USA

23 Department of Epidemiology, School of Public Health, University of Washington, Seattle, WA, USA

24 International Epidemiology Institute, 1455 Research Blvd., Suite 550, Rockville, MD 20850, USA

25 Mayo Clinic, Rochester, MN, USA

26 Department of Urology, University Hospital Ulm, Ulm, Germany

27 Institute of Human Genetics, University Hospital Ulm, Ulm, Germany 
grade cancer (OR 1.16;0.99, 1.37; $p=0.07)$ [15]. These data suggest that the comparable observational associations between adiposity phenotypes and prostate cancer outcomes are not confounded. However, the evidence for these effects was weak, originating from a single study of moderate size (1,550 cases) using only a single variant, and there is no evidence we are aware of linking genetic variation in height with prostate cancer. The results, therefore, require confirmation and extension in larger datasets, using height- and additional adiposity-related genetic variants.

Our aim was to use genetic variation in height and body mass index (BMI) as unconfounded exposures to investigate the causal associations of obesity and stature with prostate cancer risk and outcomes (Mendelian randomization [20]). Instead of the single-variant, single-sample approach used previously, we employ a more powerful two-sample, multiple-variant approach [21, 22] that combines several polymorphisms (based on confirmed genetic variant-intermediate phenotype associations $[23,24])$ into genetic risk scores in order to explain more of the variance in BMI and height exposures and thus increase power and avoid weak instrument bias [21].

\section{Methods}

Participants in this study were men of European genotypic ancestry from 22 independent studies contributing to the international PRACTICAL Consortium (PRostate cancer AssoCiation group To Investigate Cancer-Associated

28 Brigham and Women's Hospital/Dana-Farber Cancer Institute, 45 Francis Street-ASB II-3, Boston, MA 02115, USA

29 Washington University, St. Louis, Missouri

30 International Hereditary Cancer Center, Department of Genetics and Pathology, Pomeranian Medical University, Szczecin, Poland

31 Division of Genetic Epidemiology, Department of Medicine, University of Utah School of Medicine, Salt Lake City, UT, USA

32 Division of Clinical Epidemiology and Aging Research, German Cancer Research Center (DKFZ), Heidelberg, Germany

33 Division of Preventive Oncology, German Cancer Research Center (DKFZ), Heidelberg, Germany

34 German Cancer Consortium (DKTK), German Cancer Research Center (DKFZ), Heidelberg, Germany

35 Division of Cancer Prevention and Control, H. Lee Moffitt Cancer Center, 12902 Magnolia Dr., Tampa, FL, USA

36 Molecular Medicine Center and Department of Medical Chemistry and Biochemistry, Medical University Sofia, 2 Zdrave St, 1431 Sofia, Bulgaria
aLterations in the genome, http://www.practical.ccge. medschl.cam.ac.uk) [25, 26]. The individual studies are described at http://www.nature.com/ng/journal/v45/n4/ extref/ng.2560-S1.pdf, with summary data in Table 1. Of the studies within the PRACTICAL Consortium at the time of data extraction, we excluded the EPIC-Norfolk, CAPS, and SEARCH studies (involving 3,005 cases and 2,825 controls), because they were included in the genome-wide studies that originally detected the height and BMI genetic variants [23, 24]. Cancers were categorized as low grade (Gleason score $\leq 6$ ) or high grade (Gleason score $\geq 7$ ) and localized (T1 or T2 on TNM staging, or if not available, "localized" on SEER staging) or advanced (T3 or T4 on TNM staging, or if not available, "regional" or "distant" on SEER staging). All studies met the appropriate ethical criteria for each country in accordance with the principles embodied in the Declaration of Helsinki.

\section{Genotyping}

Genotyping was carried out using an Illumina Custom Infinium genotyping array (iCOGS), designed for the Collaborative Oncological Gene-environment Study (COGS), and consisted of 211,155 SNPs (details at http:// ec.europa.eu/research/health/medical-research/cancer/fp7projects/cogs_en.html) [25, 26]. This array was devised to evaluate genetic variants for associations with breast, ovarian, and prostate cancer; 68,638 were specifically chosen for their potential relevance to prostate cancer. The remaining 125,877 SNPs measured by the array were chosen for

37 Australian Prostate Cancer Research Centre-Qld, Institute of Health and Biomedical Innovation and School of Biomedical Sciences, Queensland University of Technology, Brisbane, QLD, Australia

38 Department of Genetics, Portuguese Oncology Institute, Porto, Portugal

39 Biomedical Sciences Institute (ICBAS), Porto University, Porto, Portugal

40 The University of Surrey, Guildford, Surrey GU2 7XH, UK

41 Department of Applied Health Research, University College London, 1-19 Torrington Place, London WC1E 7HB, UK

42 Commissariat à l'Energie Atomique, Center National de Génotypage, Evry, France

43 McGill University-Génome Québec Innovation Centre, Montreal, Canada

44 Bristol Nutrition Biomedical Research Unit, National Institute for Health Research, Bristol, UK 
Table 1 Clinical characteristics of the men in each of the studies contributing to the PRACTICAL consortium $(n=41,062)$

\begin{tabular}{|c|c|c|c|c|c|c|c|c|c|c|}
\hline \multirow[t]{2}{*}{ Study } & \multirow[t]{2}{*}{ Country } & \multicolumn{2}{|l|}{$n$} & \multicolumn{2}{|l|}{ Mean } & \multicolumn{5}{|l|}{$\%$} \\
\hline & & Controls & Cases & $\begin{array}{l}\text { Age at } \\
\text { diagnosis } \\
\text { (years) }\end{array}$ & $\begin{array}{l}\text { PSA at } \\
\text { diagnosis } \\
(\mathrm{ng} / \mathrm{ml})\end{array}$ & $\begin{array}{l}\text { Screen } \\
\text { detected }^{\mathrm{b}} \\
(\%)\end{array}$ & $\begin{array}{l}\text { Family history } \\
\text { prostate cancer }\end{array}$ & $\begin{array}{l}\text { Gleason } \\
\text { score } \\
8-10\end{array}$ & $\begin{array}{l}\text { Advanced } \\
\text { stage (T3 or } \\
\text { T4) }\end{array}$ & $\begin{array}{l}\text { Distant } \\
\text { spread } \\
\text { (SEER) }\end{array}$ \\
\hline CPCS1 & Denmark & 2,771 & 848 & 69.5 & 48.0 & 0.0 & 8.2 & 35.0 & - & - \\
\hline CPCS2 & Denmark & 1,009 & 265 & 64.9 & 36.0 & 0.0 & 14.7 & 10.6 & - & - \\
\hline EPIC & Europe $^{\mathrm{a}}$ & 1,079 & 722 & 64.9 & 19.7 & 0.0 & - & 3.6 & 3.8 & 0.9 \\
\hline ESTHER & Germany & 318 & 313 & 65.5 & 58.7 & 61.9 & 8.9 & 9.1 & 26.4 & 3.4 \\
\hline FHCRC & USA & 730 & 761 & 59.7 & 16.1 & - & 21.7 & 10.4 & - & 2.6 \\
\hline IPO-Porto & Portugal & 66 & 183 & 59.3 & 8.3 & 82.8 & 20.0 & 15.8 & 64.5 & 0.0 \\
\hline MAYO & USA & 488 & 767 & 65.2 & 15.5 & 73.7 & 29.1 & 33.0 & 44.4 & 0.5 \\
\hline MCCS & Australia & 1,169 & 1,698 & 58.5 & 136.6 & - & 23.4 & 11.0 & 14.0 & 0.8 \\
\hline MEC & USA & 829 & 819 & 69.5 & - & - & 13.0 & 36.0 & - & 2.8 \\
\hline MOFFITT & USA & 100 & 412 & 64.9 & 7.3 & 0.0 & 22.9 & 11.2 & 3.5 & 0.5 \\
\hline PCMUS & Bulgaria & 140 & 151 & 69.3 & 32.5 & 21.2 & 5.3 & 29.8 & 42.4 & 18.5 \\
\hline PPF-UNIS & UK & 176 & 244 & 68.9 & 32.0 & - & 25.3 & 10.9 & 25.7 & 9.0 \\
\hline Poland & Poland & 359 & 438 & 67.7 & 40.2 & 0.0 & 10.6 & 14.0 & 36.8 & 2.8 \\
\hline ProMPT & UK & 1 & 166 & 66.3 & 33.0 & 0.0 & 34.6 & 18.9 & 32.7 & 7.8 \\
\hline ProtecT & UK & 1,474 & 1,542 & 62.8 & 9.6 & 100.0 & 7.9 & 5.7 & 11.3 & 0.4 \\
\hline $\begin{array}{l}\text { QLD/ } \\
\text { ProsCan }\end{array}$ & Australia & 87 & 186 & 61.3 & 6.7 & - & 36.2 & 4.0 & 0.0 & 0.0 \\
\hline STHMI & Sweden & 2,224 & 2,002 & 66.2 & - & - & 20.2 & 10.2 & 14.2 & 1.6 \\
\hline TAMPERE & Finland & 2,413 & 2,753 & 68.2 & 69.1 & 46.8 & - & 15.4 & 21.0 & 7.3 \\
\hline UKGPCS & UK & 4,182 & 4,549 & 63.8 & 83.9 & 28.9 & 23.4 & 17.2 & 32.9 & 10.7 \\
\hline ULM & Germany & 354 & 601 & 63.8 & 19.1 & - & 44.9 & 15.5 & 39.9 & 1.1 \\
\hline UTAH & USA & 245 & 440 & 62.6 & - & - & 51.4 & 16.1 & - & 4.7 \\
\hline WUGS & USA & 0 & 988 & 60.8 & 6.2 & - & 42.3 & 7.9 & 24.2 & 0.1 \\
\hline
\end{tabular}

Studies: Copenhagen Prostate Cancer Study 1 (CPCS1); Copenhagen Prostate Cancer Study 2 (CPCS2); European Prospective Investigation Into Cancer and Nutrition (EPIC); Epidemiological investigations of the chances of preventing, recognizing early and optimally treating chronic diseases in an elderly population (ESTHER); Fred Hutchinson Cancer Research Center (FHCRC); Portuguese Oncology Institute, Porto (IPOPorto); Mayo Clinic (MAYO); Melbourne Collaborative Cohort Study (MCCS); Multiethnic Cohort Study (MEC); The Moffitt Group (MOFFITT); Prostate Cancer study Medical University Sofia (PCMUS); Prostate Project Foundation-Postgraduate Medical School, Surrey (PPFUNIS); The Poland Group (Poland); Prostate cancer: Mechanisms of progression and Treatment (ProMPT); Prostate testing for cancer and Treatment (ProtecT); Retrospective Queensland Study (QLD) and the Prostate Cancer Supportive Care and Patient Outcomes Project (ProsCan); Stockholm 1 (STHMI); Finnish Genetic Predisposition to Prostate Cancer Study (TAMPERE); U.K. Genetic Prostate Cancer Study and The Prostate Cancer Research Foundation Study (UKGPCS); Familial Prostate Cancer Study Ulm (ULM); UTAH Study (UTAH); Washington University Genetics Study (WUGS)

a Germany, Greece, Italy, Netherlands, Spain, Sweden, Oxford

b Studies with $0 \%$ screen detected are entirely based on clinically detected cases, and studies with no information about method of detection have a missing value; 12,231 individuals have information of method of detection

relevance to other cancers and common SNPs which had been previously associated with any trait. Participants with low call rates $(<95 \%)$ and high or low heterozygosity $\left(p<1 \times 10^{-5}\right)$ were excluded; 201,598 SNPs passed quality control for the European ancestry samples. We used these genotypic data to impute 2.6 million SNPs based on the HapMap 2 CEU reference panel and using IMPUTE2 software [27]. We excluded poorly imputed SNPs $\left(R^{2}<0.3\right)$

\section{Constructing genetic risk scores for BMI and height}

We constructed genetic risk scores [21] for height and BMI using 179 and 32 variants, respectively, previously reported in genome-wide association studies (GWAS) to be associated with height [23] and BMI [24]. We used allele dosages from the imputation to construct the genetic risk score. The dosages code each SNP continuously from 0 to 2 , and the dosages across all SNPs are summed to estimate 
the number of height or BMI increasing risk alleles per man. Each genetic variant was given a weight equal to the effect of the variant on height or BMI reported by the previous GWASs [23, 24]. The genetic risk score is therefore a weighted sum of the estimated number of risk alleles across several genotypes, which can improve the precision of the results compared to an unweighted score [21]. Supplementary Tables 1 and 2 provide details of the variants used and weights assigned.

\section{Statistical analysis}

We estimated associations of the genetic risk scores with measured height and BMI using linear regression based on 1,270 men without prostate cancer [i.e., prostate-specific antigen (PSA) level $<3.0 \mathrm{ng} / \mathrm{ml}$ or men with a raised PSA but who were biopsy negative] from the ProtecT population-based study $[15,28]$, one of the PRACTICAL studies with the relevant phenotypic data in a well-defined control group. We computed $F$ statistics and $R^{2}$ values (the proportion of variation in height and BMI explained by the genetic risk score) from the linear regression to evaluate the strength of the genetic risk score instruments in a population of men at increased risk of cancer. We had 82 and $78 \%$ power to detect an odds ratio of 1.12 and 1.25 for the effects of height and BMI on prostate cancer risk, assuming a sample size of 41,062 and that the genetic risk scores explained 6.31 and $1.46 \%$ of the variation in height and BMI, respectively [29].

We investigated associations of the phenotypes (height and $\mathrm{BMI}$ ) and the genetic risk scores (for height and BMI) with measured covariables in the ProtecT cases to assess whether the scores were likely to be independent of potential environmental confounding factors and to assess the potential for pleiotropy (genetic confounding). We included the following potential confounders: diabetes; occupation (managerial vs. nonmanagerial); exercise (strenuous; moderate or strenuous, vs. light); alcohol intake (three or more drinks a week vs. two or less); smoking (passive, current, or ex-smoker vs. never); diagnostic PSA level; and age at recruitment. We investigated whether the scores predicted circulating insulin-like growth factor (IGF-I) levels (a potential mechanism linking size with prostate cancer $[13,14])$ and benign prostatic hyperplasia (a potential cause of detection bias [30]).

We assessed the relationship of the height and BMI genetic risk scores with prostate cancer risk, stage, and grade across all 22 eligible studies contributing to PRACTICAL using logistic regression to compute ORs, with robust standard errors to account for within-study clustering. The genetic risk score was standardized to mean zero and standard deviation one, and the ORs were parameterized as the change in outcome per standard deviation increase in genetic risk score. In a secondary analysis, we also computed ORs comparing the highest versus the lowest quintile of each genetic risk score to illustrate the differences in outcomes between the extremes of the BMI or height allele score distributions. This reduced form, the association of the instrument (the genetic risk score) with the outcome, is a valid test of the direction of the effect of a phenotype on an outcome [31, 32]. We investigated between-study heterogeneity by estimating the logistic regressions individually for each study and using the Stata metan command to estimate the $I^{2}$ statistic assuming a fixed-effect model. As we found little evidence of heterogeneity, we report the ORs from the logistic regression analyses conducted across the 22 included studies.

We calculated ORs for all prostate cancers and then separately for localized versus advanced and low-grade (Gleason score $\leq 6$ ) versus high-grade (Gleason score $\geq 7$ ) cancers. Among men with prostate cancer (case-only analysis), we estimated associations of the standardized height and BMI weighted genetic risk scores with all-cause and prostate cancer-specific mortality using Cox proportional hazards regression, with age at diagnosis as the start date and age at death or final follow-up timepoint as the exit date, with standard errors clustered by study (there was no evidence that the proportional hazards assumption was violated). We tested for heterogeneity in association of the genetic risk scores with localized versus advanced and low- versus high-grade prostate cancer risk using a multivariate logistic regression. We tested for heterogeneity in the association of the genetic risk scores and survival of patients with localized versus advanced and low versus high grade using the test proposed by Altman and Bland [33].

\section{Sensitivity analyses}

We assessed the potential for pleiotropy, since it is possible that variants identified in the genome-wide scans are not specific for height or BMI and have effects on the prostate cancer outcomes independent of their effects on the exposures (height or BMI) [34]. If the no-effect modification assumption holds, similar instrumental variable estimates acquired using independent instruments would provide suggestive evidence against an influence of pleiotropic effects, as it is unlikely that they have shared pleiotropy [21, 35]. Therefore, as a sensitivity analysis we tested for evidence of heterogeneity across different SNPs for each of our baseline results which differed from the null. We generated two independent genetic instruments for BMI using (1) rs1558902 in FTO, the individual SNP with the largest effect size in the meta-analysis of GWASs for BMI [24] and (2) a weighted allelic score constructed from the remaining BMI-associated SNPs. We randomly 
split the height allele score into two independent weighted scores containing 89 and 90 SNPs (for details of the SNPs in each score see Supplementary Table 3). The height SNPs were in linkage equilibrium, and hence, these scores were statistically independent. We estimated the association of each instrument with prostate cancer and tested for heterogeneity [33].

The top eight principal components that reflect the population's genetic structure were estimated and included as covariates in adjusted regression models to account for confounding by population stratification. We also report the associations of the genetic risk scores with survival additionally adjusted for PSA level, grade, and stage. We ran all statistical analyses in Stata version 13.1 (StataCorp LP, 2014, College Station, TX).

\section{Results}

Our sample consisted of 20,848 cases and 20,214 controls of European genetic descent, with genotypic data from the iCOGs array that had passed quality control and was not included in the GIANT consortium used to generate the genetic risk scores (EPIC-Norfolk, CAPS, and SEARCH studies) (Table 1). The percentage of high-grade cancers reported varied between studies (3.6-35.0\%), as did the proportion of advanced stage cancers $(3.5-64.5 \%)$. The case-only survival analysis was based on 15,491 men, because 5,357 of the 20,848 men with prostate cancer did not have age at entry or exit in the dataset.

\section{Associations of genetic risk scores with measured height and BMI in ProtecT}

Associations of the weighted genetic risk scores with height and BMI in the ProtecT sub-sample are shown in Table 2. The results with the unweighted score were similar, but less precise (results not shown). The genetic risk scores explained 6.31 and $1.46 \%$ of the variability in height and BMI, respectively, consistent with previous studies [23, 24], which suggest that the genetic risk scores are strong instruments for the phenotypes.

\section{Associations of genetic risk scores with potential confounders in ProtecT}

Taller men were more likely to have managerial jobs, have lower PSA levels, and have joined the ProtecT study at a younger age (Table 3), but there was little evidence that the height genetic risk score was associated with any of the confounders except benign hypertrophy of the prostate (all $p$ values $>0.05$ ). Heavier men were more likely to have diabetes; be inactive; drink fewer than 3 drinks a week; be a nonsmoker; and have lower IGF-I levels (Table 3), but we found little evidence that the BMI genetic risk score was associated with any of the potential confounders (all $p$ values $>0.05$ )

\section{Association of the genetic risk scores and prostate cancer risk and mortality}

Associations of the genetic risk scores for height and BMI with prostate cancer risk are shown in Table 4, with the study-specific estimates in Supplementary Figures 1-10. There was little consistent evidence that the genetic risk score for height was associated with prostate cancer, although there was weak evidence of an inverse association with advanced prostate cancer [OR, per standard deviation increase in height genetic score 0.96; $95 \%$ CI 0.93, 0.99, $p=0.01 ; p$ heterogeneity, advanced vs. localized 0.05]. There was weak evidence that the genetic risk score for BMI was associated with a reduced prostate cancer risk (OR per standard deviation increase in BMI genetic score 0.98; $95 \%$ CI $0.96,1.00 ; p=0.07$ ), but little evidence of variation by stage or grade ( $p$ heterogeneity 0.64 and 0.13 , respectively).

The height genetic risk score was associated with an increase in prostate cancer-specific mortality among men with low-grade disease (OR per standard deviation increase in the height score 1.13; $95 \%$ CI 1.08, 1.20, $p$ heterogeneity, low vs. high grade $<0.001$ ), but there was little evidence of associations with all-cause mortality (Table 5). The BMI genetic risk score was associated with higher allcause mortality among low-grade disease (OR per standard deviation increase in the BMI score 1.08; $95 \%$ CI 1.03, $1.14, p$ heterogeneity low vs. high grade $=0.03$ ), but there was little evidence of associations with prostate cancerspecific mortality.
Table 2 Association of weighted height and BMI genetic risk scores with measured height and weight in 907 controls in ProtecT [28]

\begin{tabular}{lllllll}
\hline & $n$ & Mean difference & $95 \%$ CI & \multicolumn{2}{c}{$r^{2}(\%)$} & $F$-statistic \\
\cline { 3 - 5 } & & Lower limit & Upper limit & \\
\hline Height & 907 & 0.26 & 0.20 & 0.33 & 6.31 & 67.6 \\
BMI & 901 & 0.12 & 0.06 & 0.19 & 1.46 & 13.6 \\
\hline
\end{tabular}

To allow direct comparison of effect sizes, BMI and height phenotypic measurements and the genetic risk scores were normalized to mean zero and standard deviation one 
Table 3 Odds ratio or change in continuous variable covariates per standard deviation change in either height and BMI (phenotypes) or genetic risk scores for height and BMI (instruments) in the ProtecT study cases [28]

\begin{tabular}{|c|c|c|c|c|c|c|c|c|c|}
\hline \multirow[b]{3}{*}{ Standardized height } & \multirow[t]{3}{*}{$n$} & \multicolumn{4}{|c|}{ Observed phenotype $^{a}$} & \multicolumn{4}{|c|}{ Genetic risk scores $^{\mathrm{a}}$} \\
\hline & & $\begin{array}{l}\text { Effect } \\
\text { estimate }\end{array}$ & \multicolumn{2}{|c|}{ Confidence interval $^{\mathrm{b}}$} & \multirow[t]{2}{*}{$p$ value } & \multirow{2}{*}{$\begin{array}{l}\text { Effect } \\
\text { estimate } \\
\text { Odds rati }\end{array}$} & \multicolumn{2}{|c|}{ Confidence interval $^{\mathrm{b}}$} & \multirow[t]{2}{*}{$p$ value } \\
\hline & & \multicolumn{3}{|c|}{ Odds ratio $^{c}$} & & & Lower & Upper & \\
\hline \multicolumn{10}{|l|}{ Binary variables } \\
\hline Diabetes & 726 & 0.91 & 0.64 & 1.30 & 0.62 & 0.94 & 0.70 & 1.25 & 0.66 \\
\hline Managerial occupation & 818 & 1.21 & 1.06 & 1.40 & 0.006 & 0.91 & 0.79 & 1.04 & 0.17 \\
\hline Strenuous exercise & 621 & 1.13 & 0.96 & 1.33 & 0.13 & 1.03 & 0.87 & 1.21 & 0.75 \\
\hline Moderate or strenuous exercise & 621 & 1.15 & 0.96 & 1.37 & 0.12 & 1.01 & 0.85 & 1.20 & 0.90 \\
\hline$\geq 3$ drinks in the last week & 820 & 1.13 & 0.98 & 1.30 & 0.09 & 1.05 & 0.91 & 1.22 & 0.47 \\
\hline Passive smoker & 752 & 1.03 & 0.89 & 1.19 & 0.72 & 1.00 & 0.86 & 1.16 & 0.99 \\
\hline Ever smoker & 780 & 1.10 & 0.95 & 1.27 & 0.21 & 1.08 & 0.93 & 1.25 & 0.33 \\
\hline Current smoker & 552 & 1.09 & 0.89 & 1.35 & 0.40 & 1.21 & 0.97 & 1.51 & 0.08 \\
\hline Benign hypertrophy of the prostate & 704 & 0.77 & 0.58 & 1.02 & 0.07 & 1.38 & 1.01 & 1.88 & 0.05 \\
\hline & & \multicolumn{4}{|c|}{ Regression coefficient $^{\mathrm{c}}$} & \multicolumn{4}{|c|}{ Regression coefficient $^{c}$} \\
\hline \multicolumn{10}{|l|}{ Continuous variables } \\
\hline PSA (ng/ml) & 828 & -1.15 & -2.01 & -0.29 & 0.009 & -0.31 & -1.32 & 0.70 & 0.55 \\
\hline IGF-I (ng/ml) & 718 & 1.80 & -2.23 & 5.83 & 0.38 & -2.53 & -6.31 & 1.25 & 0.19 \\
\hline Age (years) & 1,109 & -0.53 & -0.83 & -0.24 & $<0.001$ & 0.07 & -0.23 & 0.38 & 0.64 \\
\hline Standardized BMI & & \multicolumn{4}{|c|}{ Odds ratio $^{c}$} & \multicolumn{4}{|c|}{ Odds ratio $^{c}$} \\
\hline \multicolumn{10}{|l|}{ Binary variables } \\
\hline Diabetes & 724 & 1.90 & 1.45 & 2.48 & $<0.001$ & 1.16 & 0.86 & 1.57 & 0.33 \\
\hline Managerial occupation & 813 & 0.96 & 0.83 & 1.10 & 0.54 & 0.91 & 0.79 & 1.05 & 0.20 \\
\hline Strenuous exercise & 617 & 0.91 & 0.77 & 1.08 & 0.28 & 1.05 & 0.89 & 1.23 & 0.57 \\
\hline Moderate or strenuous exercise & 617 & 0.80 & 0.66 & 0.96 & 0.02 & 1.01 & 0.85 & 1.20 & 0.94 \\
\hline$\geq 3$ drinks in the last week & 814 & 0.87 & 0.75 & 1.01 & 0.07 & 0.90 & 0.78 & 1.04 & 0.17 \\
\hline Passive smoker & 748 & 1.12 & 0.97 & 1.30 & 0.13 & 0.97 & 0.84 & 1.12 & 0.65 \\
\hline Ever smoker & 776 & 1.09 & 0.93 & 1.27 & 0.29 & 1.09 & 0.94 & 1.27 & 0.25 \\
\hline Current smoker & 548 & 0.71 & 0.54 & 0.94 & 0.02 & 1.18 & 0.95 & 1.48 & 0.13 \\
\hline \multirow[t]{2}{*}{ Benign hypertrophy of the prostate } & 700 & 0.92 & 0.69 & 1.23 & 0.56 & 0.94 & 0.71 & 1.25 & 0.66 \\
\hline & & \multicolumn{4}{|c|}{ Regression coefficient $^{\mathrm{c}}$} & \multicolumn{4}{|c|}{ Regression coefficient $^{c}$} \\
\hline \multicolumn{10}{|l|}{ Continuous variables } \\
\hline PSA (ng/ml) & 822 & -0.25 & -1.55 & 1.05 & 0.70 & -0.21 & -0.96 & 0.54 & 0.58 \\
\hline IGF-I (ng/ml) & 714 & -5.38 & -9.12 & -1.64 & 0.005 & 1.77 & -1.97 & 5.51 & 0.35 \\
\hline Age (years) & 1,101 & -0.28 & -0.60 & 0.04 & 0.08 & -0.04 & -0.33 & 0.25 & 0.79 \\
\hline
\end{tabular}

${ }^{a}$ Observed phenotypes and genetic risk scores normalized to mean zero and standard deviation one

b Robust standard errors

${ }^{c}$ Odds ratio or change in continuous variable per standard deviation change in height and BMI (phenotype or genetic risk score) 
Table 4 Odds ratio of prostate cancer per one standard deviation change in height or BMI genetic score

\begin{tabular}{|c|c|c|c|c|c|c|c|c|c|c|}
\hline & \multirow[t]{3}{*}{$n$} & \multicolumn{4}{|c|}{ Unadjusted } & \multicolumn{5}{|c|}{ Adjusted $^{\mathrm{a}}$} \\
\hline & & \multirow[t]{2}{*}{$\begin{array}{l}\text { Odds } \\
\text { ratio }^{c}\end{array}$} & \multicolumn{2}{|c|}{$\begin{array}{l}\text { Confidence } \\
\text { interval }^{\mathrm{b}}\end{array}$} & \multirow[t]{2}{*}{$p$ value } & \multirow[t]{2}{*}{$\begin{array}{l}\text { Odds } \\
\text { ratio }^{c}\end{array}$} & \multicolumn{2}{|c|}{$\begin{array}{l}\text { Confidence } \\
\text { interval }^{\mathrm{b}}\end{array}$} & \multirow[t]{2}{*}{$p$ value } & \multirow[t]{2}{*}{$p$ heterogeneity ${ }^{d}$} \\
\hline & & & Lower & Upper & & & Lower & Upper & & \\
\hline \multicolumn{11}{|l|}{ Height } \\
\hline Controls & 20,214 & 1.00 & - & - & - & 1.00 & - & - & - & - \\
\hline All prostate cancers & 20,848 & 0.96 & 0.91 & 1.01 & 0.12 & 0.99 & 0.97 & 1.01 & 0.23 & \\
\hline Localized prostate cancer & 12,975 & 0.96 & 0.88 & 1.03 & 0.27 & 1.00 & 0.98 & 1.02 & 0.72 & 0.05 \\
\hline Advanced prostate cancer & 4,325 & 0.90 & 0.83 & 0.98 & 0.02 & 0.96 & 0.93 & 0.99 & 0.01 & \\
\hline Low-grade prostate cancer & 8,784 & 0.96 & 0.90 & 1.02 & 0.20 & 0.99 & 0.96 & 1.01 & 0.30 & 0.55 \\
\hline High-grade prostate cancer & 8,230 & 0.97 & 0.92 & 1.02 & 0.26 & 1.00 & 0.98 & 1.02 & 0.85 & \\
\hline \multicolumn{11}{|l|}{$B M I$} \\
\hline Controls & 20,214 & 1.00 & - & - & - & 1.00 & - & - & - & - \\
\hline All prostate cancers & 20,848 & 0.98 & 0.96 & 1.01 & 0.15 & 0.98 & 0.96 & 1.00 & 0.07 & \\
\hline Localized prostate cancer & 12,975 & 0.98 & 0.96 & 1.00 & 0.10 & 0.98 & 0.96 & 1.00 & 0.05 & 0.64 \\
\hline Advanced prostate cancer & 4,325 & 1.01 & 0.97 & 1.05 & 0.69 & 1.01 & 0.97 & 1.05 & 0.62 & \\
\hline Low-grade prostate cancer & 8,784 & 0.98 & 0.94 & 1.02 & 0.25 & 0.97 & 0.94 & 1.00 & 0.09 & 0.13 \\
\hline High-grade prostate cancer & 8,230 & 1.00 & 0.97 & 1.02 & 0.69 & 1.00 & 0.98 & 1.01 & 0.65 & \\
\hline
\end{tabular}

\section{Sensitivity analysis}

\section{Prostate cancer risk}

There was little evidence that men with height variants with larger effects on the height phenotype were more or less likely to be diagnosed with prostate cancer $\left(r^{2}=0.0071\right) \quad$ (Fig. 1; see Supplementary Table 4 for associations of each of the height variants with prostate cancer risk). There was some evidence that BMI variants with the largest effect on BMI were most strongly inversely associated with prostate cancer $\left(r^{2}=0.0231\right)$ (Fig. 2; Supplementary Table 5 for associations of each of the BMI variants with prostate cancer risk). We found little evidence of heterogeneity in the effect of BMI proxied by independent instruments based on independent genetic scores made up of different sets of SNPs. Individuals with more BMI increasing FTO alleles were less likely to be diagnosed with prostate cancer (OR per BMI increasing allele rs1558902-A 0.97; $95 \%$ CI 0.94, 1.01, $p=0.10$ ). In line with this, the allele score based on the remaining 31 BMI SNPs was also inversely associated with prostate cancer (OR per standard deviation increase in BMI genetic score excluding FTO 0.99; $95 \%$ CI 0.97, 1.01, $p=0.33$; $p$ value for heterogeneity between the two independent instruments $=0.38$ ).

\section{All-cause mortality}

There was little evidence that the two sets of independent height or BMI allele scores were associated with an increased risk of all-cause mortality in men diagnosed with prostate cancer (see Supplementary Table 10 for associations of all 179 height SNPs and all-cause mortality and Supplementary Table 7 for associations of each of the 32 BMI SNPs with all-cause mortality and prostate cancerspecific mortality).

\section{Prostate cancer-specific mortality}

Both sets of independent height allele scores were associated with an increased risk of prostate cancer-specific mortality in men diagnosed with low-grade prostate cancer (hazard ratio per one standard deviation increase in the first height allele score 1.10; $95 \%$ CI 1.03, 1.19, $p=0.008$; and in the second height allele score 1.09; $95 \%$ CI 1.05, $1.13, p<0.001 ; p$ value for heterogeneity $=0.86$; see 
Table 5 Hazard ratio of all-cause and prostate cancer-specific mortality among men with prostate cancer per one standard change in height or BMI genetic score

\begin{tabular}{|c|c|c|c|c|c|c|c|c|c|c|c|c|}
\hline & \multirow{3}{*}{$\begin{array}{l}\text { Number of } \\
\text { participants }\end{array}$} & \multirow{3}{*}{$\begin{array}{l}\text { Number } \\
\text { of } \\
\text { failures }\end{array}$} & \multirow{3}{*}{$\begin{array}{l}\text { Years at } \\
\text { risk } \\
(1000 \mathrm{~s})\end{array}$} & \multicolumn{4}{|c|}{ Unadjusted } & \multicolumn{5}{|c|}{ Adjusted $^{\mathrm{a}}$} \\
\hline & & & & \multirow[t]{2}{*}{$\begin{array}{l}\text { Hazard } \\
\text { ratio }^{c}\end{array}$} & \multicolumn{2}{|c|}{$\begin{array}{l}\text { Confidence } \\
\text { interval }^{b}\end{array}$} & \multirow[t]{2}{*}{$p$ value } & \multirow[t]{2}{*}{$\begin{array}{l}\text { Hazard } \\
\text { ratio }^{c}\end{array}$} & \multicolumn{2}{|c|}{$\begin{array}{l}\text { Confidence } \\
\text { interval }^{b}\end{array}$} & \multirow[t]{2}{*}{$p$ value } & \multirow[t]{2}{*}{$p$ heterogeneity ${ }^{d}$} \\
\hline & & & & & Lower & Upper & & & Lower & Upper & & \\
\hline \multicolumn{13}{|c|}{ All-cause mortality } \\
\hline \multicolumn{13}{|l|}{ Height } \\
\hline All cases & 14,649 & 3,591 & 105 & 1.02 & 0.97 & 1.08 & 0.47 & 1.00 & 0.96 & 1.04 & 0.88 & \\
\hline Localized & 8,553 & 1,447 & 65 & 1.01 & 0.93 & 1.09 & 0.81 & 1.00 & 0.93 & 1.07 & 0.97 & 0.20 \\
\hline Advanced & 3,435 & 1,332 & 25 & 1.08 & 0.98 & 1.18 & 0.11 & 1.07 & 0.99 & 1.14 & 0.07 & \\
\hline Low grade & 5,684 & 905 & 43 & 1.04 & 0.97 & 1.11 & 0.32 & 1.02 & 0.95 & 1.09 & 0.57 & 0.80 \\
\hline High grade & 5,892 & 1,365 & 36 & 1.02 & 0.97 & 1.08 & 0.36 & 1.01 & 0.96 & 1.06 & 0.71 & \\
\hline \multicolumn{13}{|l|}{ BMI } \\
\hline All cases & 14,649 & 3,591 & 105 & 1.02 & 0.99 & 1.05 & 0.18 & 1.02 & 0.99 & 1.05 & 0.23 & \\
\hline Localized & 8,553 & 1,447 & 65 & 1.04 & 0.99 & 1.10 & 0.09 & 1.04 & 0.99 & 1.10 & 0.09 & 0.28 \\
\hline Advanced & 3,435 & 1,332 & 25 & 1.01 & 0.98 & 1.04 & 0.50 & 1.01 & 0.98 & 1.05 & 0.59 & \\
\hline Low grade & 5,684 & 905 & 43 & 1.09 & 1.04 & 1.15 & 0.001 & 1.08 & 1.03 & 1.14 & 0.002 & 0.03 \\
\hline High grade & 5,892 & 1,365 & 36 & 1.00 & 0.96 & 1.05 & 0.89 & 1.00 & 0.95 & 1.05 & 0.98 & \\
\hline \multicolumn{13}{|c|}{ Prostate cancer-specific mortality } \\
\hline \multicolumn{13}{|l|}{ Height } \\
\hline All cases & 14,649 & 1,483 & 105 & 1.02 & 0.98 & 1.06 & 0.44 & 1.00 & 0.97 & 1.04 & 0.87 & \\
\hline Localized & 8,553 & 363 & 65 & 0.98 & 0.91 & 1.07 & 0.72 & 0.99 & 0.91 & 1.08 & 0.79 & 0.29 \\
\hline Advanced & 3,435 & 745 & 25 & 1.05 & 1.00 & 1.10 & 0.06 & 1.04 & 1.00 & 1.09 & 0.07 & \\
\hline Low grade & 5,684 & 188 & 43 & 1.13 & 1.06 & 1.21 & $<0.001$ & 1.13 & 1.08 & 1.20 & $<0.001$ & $<0.001$ \\
\hline High grade & 5,892 & 678 & 36 & 0.97 & 0.93 & 1.02 & 0.20 & 0.97 & 0.93 & 1.01 & 0.19 & \\
\hline \multicolumn{13}{|l|}{ BMI } \\
\hline All cases & 14,649 & 1,483 & 105 & 0.99 & 0.96 & 1.03 & 0.76 & 1.00 & 0.96 & 1.04 & 0.94 & \\
\hline Localized & 8,553 & 363 & 65 & 0.95 & 0.88 & 1.03 & 0.22 & 0.95 & 0.87 & 1.05 & 0.31 & 0.09 \\
\hline Advanced & 3,435 & 745 & 25 & 1.04 & 0.98 & 1.10 & 0.18 & 1.05 & 0.99 & 1.10 & 0.11 & \\
\hline Low grade & 5,684 & 188 & 43 & 0.95 & 0.89 & 1.01 & 0.08 & 0.95 & 0.88 & 1.01 & 0.12 & 0.03 \\
\hline High grade & 5,892 & 678 & 36 & 1.05 & 0.99 & 1.11 & 0.12 & 1.05 & 0.98 & 1.13 & 0.14 & \\
\hline
\end{tabular}

${ }^{a}$ Adjusted for the first eight principal components of population stratification

b Based in robust standard errors to account for within-study clustering

${ }^{c}$ Change in hazard ratio per standard deviation change in height and BMI genetic risk score (standardized to mean zero standard deviation one)

${ }^{\mathrm{d}}$ Localized versus advanced, or high- versus low-grade using Bland-Altman tests

Supplementary Table 8 for the association of prostate cancer-specific mortality and each of the 179 height SNPs). None of the BMI independent instruments or individual SNPs were associated with prostate cancer-specific mortality (Supplementary Table 9). Further adjusting the associations of the genetic risk scores and survival for PSA level, grade, and stage made no substantial differences to the results (Supplementary Table 10).

\section{Discussion}

We found weak evidence that genetically elevated BMI was associated with a reduced risk of prostate cancer, but that genetically elevated height was not associated with prostate cancer risk. The height and BMI allele scores were positively associated with prostate cancer-specific and allcause mortality, respectively, but only among men with low-grade disease ( $p$ heterogeneity, low- vs. high-grade prostate cancer $<0.05$ ).

Although evidence for these associations was relatively weak, the inverse relationship of BMI with prostate cancer risk is in line with both observational data [8] and our previous genetic study [15]. The latter report showed an inverse relationship of a single obesity-related SNP (FTO rs9939609) with overall- and low-grade prostate cancer in ProtecT, a much smaller population-based sample of 1,550 screen-detected prostate cancers and 1,815 controls [15]. We found inverse associations of a related SNP in FTO (rs1558902, which is in linkage disequilibrium with 


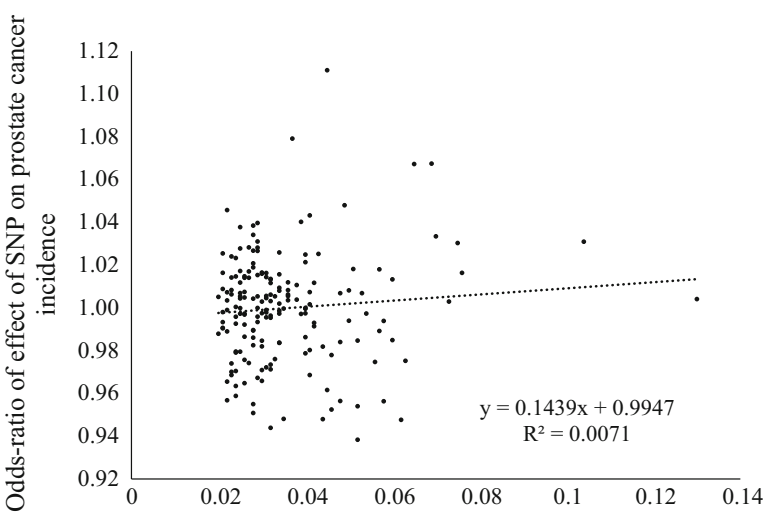

Effect of SNP on height (scale standard deviation increase in height)

Fig. 1 Scatter plot of effects of SNPs on prostate cancer risk by their effects on height

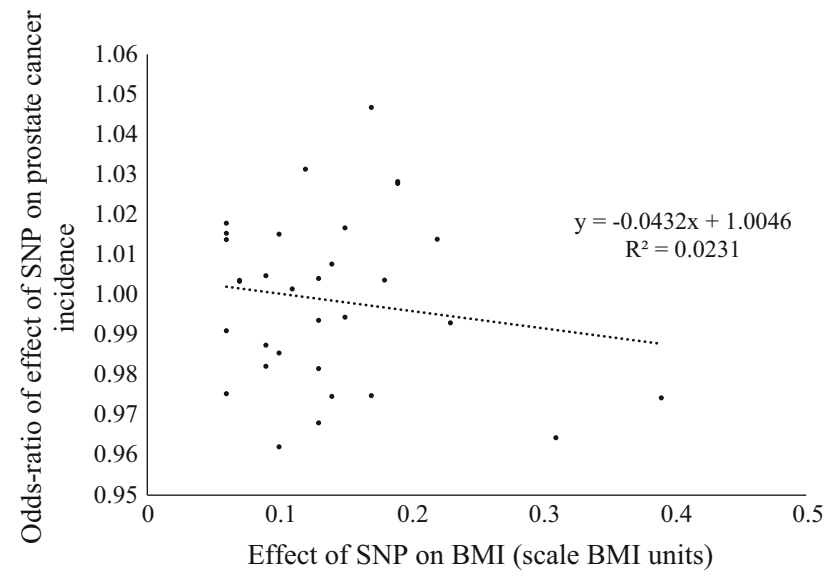

Fig. 2 Scatter plot of effects of SNPs on prostate cancer risk by their effects on BMI

rs9939609 at $\left.r^{2}=0.90\right)$ with overall and low-grade prostate cancer risk (individuals with more BMI increasing alleles had a reduced risk of all prostate cancer and lowgrade prostate cancer, respectively (OR $0.97 ; 95 \%$ CI $0.94,1.00 ; p=0.10$, and OR $0.95 ; 95 \%$ CI $0.90,1.00$; $p=0.06$ ). A previous study that created genetic risk scores for BMI using 24 of the 32 SNPs from the BMI GWAS [36] observed ORs for the BMI risk scores of 1.00 (95\% CI $0.97,1.04 ; p=0.94$ ) for the unweighted score and 1.07 (95\% CI $0.91,1.25 ; p=0.41)$ for the weighted score, but the effect estimates were imprecise as the study only included 871 cases and 906 controls.

To determine whether our findings reflect clinically important differences in disease risk, we rescaled the results to report the effects of one standard deviation changes in height and one $\mathrm{kg} / \mathrm{m}^{2}$ increases in BMI using the coefficients for the effects of the SNPs on height and BMI reported by Lango Allen et al. [23] and Speliotes et al. [24], respectively. Our results imply that a one standard deviation increase in height was associated with a $49 \%$ (95\% CI $26 \%, 76 \%, p<0.001)$ increase in prostate cancer mortality among those with low-grade disease, assuming that the height allele score explains $10 \%$ of the variation in height [23]. A $1 \mathrm{~kg} / \mathrm{m}^{2}$ increase in BMI was associated with a $4 \%(95 \%$ CI $0 \%, 8 \%, p=0.07)$ reduced risk of any prostate cancer diagnosis (assuming that the BMI allele score explains $1.45 \%$ of the variation in BMI [24] and a standard deviation of BMI of $3.5 \mathrm{~kg} / \mathrm{m}^{2}$ ). The risk of all-cause mortality was increased by $21 \%$ (95\% CI $7 \%, 37 \%$ ) per $\mathrm{kg} / \mathrm{m}^{2}$ increase in BMI among men with low-grade disease.

Our finding that genetic variation in height was not associated with an increase in prostate cancer risk is in contrast to the majority of the observational literature [6]. Indeed, we found weak evidence of an inverse association of genetic variation in height with advanced prostate cancer. However, there is some evidence of reporting bias in the previous literature; 12 of 30 prospective studies that reported effects of height on prostate cancer only in the body of the manuscript, and which were not highlighted in the title or abstract, were null (pooled OR 1.01; 0.95-1.07; $I^{2} 0 \%$ [6]. The absence of a positive association of genetic variation in height with prostate cancer risk in the current study may reflect that there is no real effect of height on prostate cancer risk or that it is the environmental (especially early-life factors $[37,38]$ ) and not genetic component of height variation that explains its positive link in some studies with incident prostate cancer [16-18, 39]. Alternatively, if height is associated with very early casefatality in men with prostate cancer, then this will remove cases from the pool available for case-control studies and could theoretically lead to selection bias causing null findings. However, prostate cancer is not generally so rapidly fatal as to preclude significant numbers of men from being included in case-control studies.

The height and BMI allele scores were positively associated, respectively, with prostate cancer-specific and allcause mortality, but only strongly among men with lowgrade disease. The positive association of BMI and height with mortality among men with prostate cancer is in line with earlier studies [9, 11, 40], although previous findings for height have been inconsistent [41, 42], and one study observed that taller men with prostate cancer had improved survival [43]. Our data suggest that only height is associated with prostate cancer-specific, rather than all-cause, mortality, and that BMI causes a broader range of deaths among men with prostate cancer.

The difference in the magnitude of effect estimates by grade does not appear to have been reported in the past and could simply be a chance finding. However, the $\mathrm{p}$ values for heterogeneity for the association of the BMI allele score with all-cause mortality and the height allele score with 
prostate cancer-specific mortality by grade were 0.03 and $<0.001$, respectively. The findings could, therefore, reflect differing determinants of progression depending on grade. This highlights the potential for modifying BMI in people with low-grade disease; however, it is likely that the genetic contribution to height explains the association of the height genetic score with prostate cancer progression. Such genetic influences could include effects on insulinlike growth factors (IGFs), which have been associated with progression of prostate cancer [44].

The strengths of the study include (1) the robust instruments developed from previous GWAS that explained a reasonable proportion of the variance in the phenotypes of interest, (2) the large sample size, and (3) the potential confounders which were associated with measured height and BMI within the ProtecT study were not associated with the genetic risk scores for height and BMI. The final point suggests that association of genetic risk scores with prostate cancer outcomes is unlikely to be explained by confounders. Evidence from genetic variation is less likely to suffer from biases that affect conventional observational studies. The generalizability of our findings is supported by broadly consistent results across the 22 studies. There are limitations to our Mendelian randomization approach, and our results could be explained by bias or confounding. For example, we used combinations of genome-wide genetic variants to proxy BMI and height, but these variants may not be specific for BMI or height and may influence prostate cancer through biological pathways other than through the phenotypes that they are acting as proxies for (genetic confounding or pleiotropy). This is plausible since even single SNPs can exert pleiotropic effects across a range of different variables [45]; for example, many BMI-associated SNPs are present at quite low levels of significance in a GWAS of c-reactive protein (CRP) [34]. However, we found similar results when we used two independent instruments for each phenotype, suggesting these results may not be due pleiotropy of a single SNP. We assumed a similar qualitative effect of the SNPs in our sample as the GIANT consortium, which is highly plausible but may not be true. We found little evidence that the genetic risk scores were associated with baseline covariates in the ProtecT study, and this is consistent with findings from the broader literature [46-49].

A reduced risk of prostate cancer associated with BMI is biologically plausible, with proposed mechanisms including the increase in estrogens (aromatase inhibitors) secondary to adiposity. However, we cannot rule out detection bias [50] arising from delayed diagnosis and more advanced stage at diagnosis in obese men; this may arise due to lower accuracy of digital rectal examination in obese men or lower PSA values caused by obesity-related hemodilution $[8,9]$.
In conclusion, our genetic data provide some evidence (albeit weak) that an elevated BMI may protect against prostate cancer risk or reduce the likelihood of it being detected (in particular, low-grade cancer), but may increase the likelihood of death in men with low-grade prostate cancer. These observations support epidemiological findings that obesity protects against a diagnosis of localized prostate cancer but increases prostate cancer mortality [8]. Previously observed positive associations of height with prostate cancer risk may reflect the environmental determinants of height. In contrast, observed positive associations of height with prostate cancer mortality may reflect the genetic determinants of height or of height determining phenotypes (e.g., IGF [39]). The findings for mortality that were only observed among men with low-grade disease are novel, and potentially clinically important, but do require replication.

Acknowledgments The Collaborative Oncological Gene-environment Study (COGS), within which the PRACTICAL consortium was assembled, would not have been possible without the contributions of the following: Per Hall (COGS); Douglas F. Easton, Paul Pharoah, Kyriaki Michailidou, Manjeet K. Bolla, Qin Wang (BCAC), Andrew Berchuck (OCAC), Rosalind A. Eeles, Douglas F. Easton, Ali Amin Al Olama, Zsofia Kote-Jarai, Sara Benlloch (PRACTICAL), Georgia Chenevix-Trench, Antonis Antoniou, Lesley McGuffog, Fergus Couch and Ken Offit (CIMBA), Joe Dennis, Alison M. Dunning, Andrew Lee, and Ed Dicks, Craig Luccarini and the staff of the Centre for Genetic Epidemiology Laboratory, Javier Benitez, Anna Gonzalez-Neira and the staff of the CNIO genotyping unit, Jacques Simard and Daniel C. Tessier, Francois Bacot, Daniel Vincent, Sylvie LaBoissière and Frederic Robidoux and the staff of the McGill University and Génome Québec Innovation Centre, Stig E. Bojesen, Sune F. Nielsen, Borge G. Nordestgaard, and the staff of the Copenhagen DNA laboratory, and Julie M. Cunningham, Sharon A. Windebank, Christopher A. Hilker, Jeffrey Meyer and the staff of Mayo Clinic Genotyping Core Facility. Funding for the iCOGS infrastructure came from: the European Community's Seventh Framework Programme under grant agreement no 223175 (HEALTH-F2-2009-223175) (COGS), Cancer Research UK (C1287/ A10118, C1287/A 10710, C12292/A11174, C1281/A12014, C5047/ A8384, C5047/A15007, C5047/A10692), the National Institutes of Health (CA128978) and Post-Cancer GWAS initiative (1U19 CA148537, 1U19 CA148065 and 1U19 CA148112-the GAME-ON initiative), the Department of Defence (W81XWH-10-1-0341), the Canadian Institutes of Health Research (CIHR) for the CIHR Team in Familial Risks of Breast Cancer, Komen Foundation for the Cure, the Breast Cancer Research Foundation, and the Ovarian Cancer Research Fund.

Funding Support for the analysis was provided by the World Cancer Research Fund (2011/419) and Cancer Research UK (C18281/ A19169). The CRUK study and the PRACTICAL consortium were supported by the Canadian Institutes of Health Research; the European Commission's Seventh Framework Programme Grant agreement number 223175 (HEALTH-F2-2009-223175); Cancer Research UK Grants C5047/A7357, C1287/A10118, C5047/A3354, C5047/ A10692, C16913/A6135; and the National Institute of Health (NIH) Cancer Post-Cancer GWAS initiative Grant No. 1 U19 CA 148537-01 (the GAME-ON initiative). The ProtecT study is funded by the UK Health Technology Assessment (HTA) Programme of the NIH 
Research (HTA 96/20/99; ISRCTN20141297). The authors thank the provision of the additional epidemiological data by the NHS R\&D Directorate supported Prodigal study and the ProMPT (Prostate Mechanisms of Progression and Treatment) collaboration which is supported by the National Cancer Research Institute (NCRI) formed by the Department of Health, the Medical Research Council and Cancer Research UK (G0500966/75466). RAE and ZKJ are supported by Cancer Research UK Grant C5047/A7357 and the NIHR Biomedical Research Centre at The Institute of Cancer Research and Royal Marsden NHS Foundation Trust. RMM was supported by the National Institute for Health Research Bristol Nutrition Biomedical Research Unit based at University Hospitals Bristol NHS Foundation Trust and the University of Bristol. FCH, DEN and JLD are NIHR Senior Investigators. The Integrative Epidemiology Unit is supported by the MRC and the University of Bristol (G0600705, MC_UU_12013/1,9). No funding body has influenced data collection, analysis, or its interpretations. The views expressed are those of the authors and not necessarily those of the NHS, the NIHR, or the Department of Health. This publication is the work of the authors, who serve as the guarantors for the contents of this paper.

\section{Compliance with ethical standards}

Conflict of interest The authors declare no conflicts of interest.

Open Access This article is distributed under the terms of the Creative Commons Attribution 4.0 International License (http://crea tivecommons.org/licenses/by/4.0/), which permits unrestricted use, distribution, and reproduction in any medium, provided you give appropriate credit to the original author(s) and the source, provide a link to the Creative Commons license, and indicate if changes were made.

\section{The PRACTICAL CONSORTIUM (in addition to those named in the author list)}

Information on the consortium can be found at http://prac tical.ccge.medschl.cam.ac.uk/.

Additional members from the consortium are: Margaret Cook $^{1}$, Angela Morgan ${ }^{2}$, Artitaya Lophatananon ${ }^{3,4}$, Cyril Fisher $^{2}$, Daniel Leongamornlert ${ }^{2}$, Edward J. Saunders ${ }^{2}$, Emma J. Sawyer ${ }^{2}$, Koveela Govindasami ${ }^{2}$, Malgorzata Tymrakiewicz ${ }^{2}$, Michelle $\mathrm{Guy}^{2}$, Naomi Livni ${ }^{2}$, Rosemary Wilkinson $^{2}$, Sara Jugurnauth-Little ${ }^{2}$, Steve Hazel ${ }^{2}$, Tokhir Dadaev $^{2}$, Melissa C. Southey ${ }^{5}$, Liesel M. Fitzgerald ${ }^{6}$, John Pedersen $^{7}$, John Hopper ${ }^{8}$, Ami Karlsson ${ }^{9}$, Carin CavalliBjoerkman ${ }^{9}$, Jan-Erik Johansson ${ }^{9}$, Jan Adolfson ${ }^{9}$, Markus Aly ${ }^{9,10}$, Michael Broms ${ }^{9}$, Paer Stattin ${ }^{9}$, Brian E. Henderson $^{11}$, Fredrick Schumacher ${ }^{11}$, Anssi Auvinen ${ }^{12}$, Kimmo Taari $^{13}$, Liisa Maeaettaenen ${ }^{14}$, Paula Kujala ${ }^{15}$, Teemu Murtola $^{16,17}$, Teuvo LJ Tammela ${ }^{17}$, Tiina Wahlfors ${ }^{18}$, Andreas Roder ${ }^{19}$, Peter Iversen ${ }^{19}$, Peter Klarskov ${ }^{20}$, Sune F. Nielsen ${ }^{21,22}$, Tim J. Key ${ }^{23}$, Hans Wallinder ${ }^{24}$, Sven Gustafsson $^{24}$, Jenny L. Donovan ${ }^{25}$, Freddie Hamdy ${ }^{26}$, Angela $\mathrm{Cox}^{27}$, Anne George ${ }^{28}$, Athene Lane ${ }^{28}$, Gemma Marsden $^{26}$, Michael Davis ${ }^{25}$, Paul Brown ${ }^{25}$, Paul Pharoah $^{29}$, Lisa B. Signorello ${ }^{31,30}$, Wei Zheng ${ }^{32}$, Shannon K. McDonnel1 ${ }^{33}$, Daniel J. Schaid ${ }^{33}$, Liang Wang ${ }^{33}$, Lori
Tillmans $^{33}$, Shaun Riska ${ }^{33}$, Thomas Schnoeller ${ }^{34}$, Kathleen Herkommer ${ }^{35}$, Manuel Luedeke ${ }^{34}$, Walther Vogel $^{36}$, Dominika Wokozorczyk ${ }^{37}$, Jan Lubiski ${ }^{37}$, Wojciech Kluzniak $^{37}$, Katja Butterbach ${ }^{38}$, Christa Stegmaier ${ }^{39}$, Bernd Holleczek $^{39}$, Babu Zachariah ${ }^{40}$, Hui-Yi Lim ${ }^{41}$, Hyun Park $^{40}$, James Haley ${ }^{40}$, Julio Pow-Sang ${ }^{40}$, Maria Rincon ${ }^{40}$, Selina Radlein ${ }^{40}$, Thomas Sellers ${ }^{40}$, Chavdar Slavov ${ }^{42}$, Aleksandrina Vlahova $^{43}$, Atanaska Mitkova ${ }^{44}$, Darina Kachakova $^{44}$, Elenko Popov ${ }^{42}$, Svetlana Christova ${ }^{43}$, Tihomir Dikov ${ }^{43}$, Vanio Mitev ${ }^{44}$, Allison Eckert ${ }^{45}$, Amanda Spurdle ${ }^{46}$, Angus Collins ${ }^{45}$, Glenn Wood ${ }^{45}$, Greg Malone $^{45}$, Judith A. Clements ${ }^{45}$, Kris Kerr ${ }^{45}$, Megan Turner $^{45}$, Pamela Saunders ${ }^{45}$, Peter Heathcote ${ }^{45}$, Srilakshmi Srinivasan ${ }^{45}$, Leire Moya ${ }^{45}$, Trina Yeadon ${ }^{45}$, Australian Prostate Cancer BioResource ${ }^{45}$, Joana Santos ${ }^{47}$, Carmen Jerónimo ${ }^{47}$, Paula Paulo ${ }^{47}$, Pedro Pinto ${ }^{47}$, Rui Henrique $^{47}$, Sofia Maia ${ }^{47}$, Agnieszka Michael ${ }^{48}$, Andrzej Kierzek $^{48}$, Huihai $\mathrm{Wu}^{48}$

${ }^{1}$ Centre for Cancer Genetic Epidemiology, Department of Public Health and Primary Care, University of Cambridge, Strangeways Laboratory, Worts Causeway, Cambridge CB1 8RN, UK, ${ }^{2}$ The Institute of Cancer Research, Sutton, UK, ${ }^{3}$ Institute of Population Health, University of Manchester, Manchester, UK, ${ }^{4}$ Warwick Medical School, University of Warwick, Coventry, UK, ${ }^{5}$ Genetic Epidemiology Laboratory, Department of Pathology, The University of Melbourne, Grattan Street, Parkville, Victoria 3010, Australia, ${ }^{6}$ Cancer Epidemiology Centre, The Cancer Council Victoria, 615 St Kilda Road, Melbourne, Victoria, Australia, ${ }^{7}$ Tissupath Pty Ltd., Melbourne,Victoria 3122, Australia, ${ }^{8}$ Centre for Epidemiology and Biostatistics, Melbourne School of Population and Global Health, The University of Melbourne, Victoria, Australia, ${ }^{9}$ Department of Medical Epidemiology and Biostatistics, Karolinska Institute, Stockholm, Sweden, ${ }^{10}$ Department of Clinical Sciences at Danderyds Hospital, Stockholm, Sweden, ${ }^{11}$ Department of Preventive Medicine, Keck School of Medicine, University of Southern California/ Norris Comprehensive Cancer Center, Los Angeles, California, USA, ${ }^{12}$ Department of Epidemiology, School of Health Sciences, University of Tampere, Tampere, Finland, ${ }^{13}$ Department of Urology, Helsinki University Central Hospital and University of Helsinki, Helsinki, Finland, ${ }^{14}$ Finnish Cancer Registry, Helsinki, Finland, ${ }^{15}$ Fimlab Laboratories, Tampere University Hospital, Tampere, Finland, ${ }^{16}$ School of Medicine, University of Tampere, Tampere, Finland, ${ }^{17}$ Department of Urology, Tampere University Hospital and Medical School, University of Tampere, Finland, ${ }^{18}$ BioMediTech, University of Tampere and FimLab Laboratories, Tampere, Finland, ${ }^{19}$ Copenhagen Prostate Cancer Center, Department of Urology, Rigshospitalet, Copenhagen University Hospital, Tagensvej 20, 7521, DK-2200 Copenhagen, Denmark, 
${ }^{20}$ Department of Urology, Herlev Hospital, Copenhagen University Hospital, Herlev Ringvej 75, DK-230 Herlev, Denmark, ${ }^{21}$ Department of Clinical Biochemistry, Herlev Hospital, Copenhagen University Hospital, Herlev Ringvej 75, DK-230 Herlev, Denmark, ${ }^{22}$ Faculty of Health and Medical Sciences, University of Copenhagen, ${ }^{23}$ Cancer Epidemiology Unit, Nuffield Department of Clinical Medicine, University of Oxford, Oxford, UK, ${ }^{24}$ Department of Epidemiology and Biostatistics, School of Public Health, Imperial College, London, UK, ${ }^{25}$ School of Social and Community Medicine, University of Bristol, Canynge Hall, 39 Whatley Road, Bristol, BS8 2PS, UK, ${ }^{26}$ Nuffield Department of Surgical Sciences, University of Oxford, Oxford, UK, Faculty of Medical Science, University of Oxford, John Radcliffe Hospital, Oxford, UK, ${ }^{27}$ CR-UK/YCR Sheffield Cancer Research Centre, University of Sheffield, Sheffield, UK, ${ }^{28}$ University of Cambridge, Department of Oncology, Box 279, Addenbrooke's Hospital, Hills Road Cambridge CB2 0QQ, UK, ${ }^{29}$ Centre for Cancer Genetic Epidemiology, Department of Oncology, University of Cambridge, Strangeways Laboratory, Worts Causeway, Cambridge, UK, ${ }^{30}$ International Epidemiology Institute, 1555 Research Blvd., Suite 550, Rockville, MD 20850, USA, ${ }^{31}$ Department of Epidemiology, Harvard School of Public Health, 677 Huntington Avenue, Boston, MA 02115, USA, ${ }^{32}$ Division of Epidemiology, Department of Medicine, Vanderbilt University Medical Center, 2525 West End Avenue, Suite 800, Nashville, TN 37232 USA, ${ }^{33}$ Mayo Clinic, Rochester, Minnesota, USA, ${ }^{34}$ Department of Urology, University Hospital Ulm, Germany, ${ }^{35}$ Department of Urology, Klinikum rechts der Isar der Technischen Universitaet Muenchen, Munich, Germany, ${ }^{36}$ Institute of Human Genetics, University Hospital Ulm, Germany, ${ }^{37}$ International Hereditary Cancer Center, Department of Genetics and Pathology, Pomeranian Medical University, Szczecin, Poland, ${ }^{38}$ Division of Clinical Epidemiology and Aging Research, German Cancer Research Center (DKFZ), 69120 Heidelberg, Germany, ${ }^{39}$ Saarland Cancer Registry, 66119 Saarbruecken, Germany, ${ }^{40}$ Department of Cancer Epidemiology, Moffitt Cancer Center, 12902 Magnolia Drive, Tampa, FL 33612, USA, ${ }^{41}$ Biostatistics Program, Moffitt Cancer Center, 12902 Magnolia Drive, Tampa, FL 33612, USA, ${ }^{42}$ Department of Urology and Alexandrovska University Hospital, Medical University, Sofia, Bulgaria, ${ }^{43}$ Department of General and Clinical Pathology, Medical University, Sofia, Bulgaria, ${ }^{44}$ Department of Medical Chemistry and Biochemistry, Molecular Medicine Center, Medical University, Sofia, 2 Zdrave Str., 1431 Sofia, Bulgaria, ${ }^{45}$ Australian Prostate Cancer Research Centre-Qld, Institute of Health and Biomedical Innovation and School of Biomedical Science, Queensland University of Technology, Brisbane, Australia, ${ }^{46}$ Molecular Cancer
Epidemiology Laboratory, Queensland Institute of Medical Research, Brisbane, Australia, ${ }^{47}$ Department of Genetics, Portuguese Oncology Institute, Porto, Portugal, ${ }^{48}$ The University of Surrey, Guildford, Surrey, GU2 7XH, UK.

\section{References}

1. Grönberg H (2003) Prostate cancer epidemiology. Lancet Lond Engl 361:859-864

2. Discacciati A, Orsini N, Wolk A (2012) Body mass index and incidence of localized and advanced prostate cancer: a doseresponse meta-analysis of prospective studies. Ann Oncol 23:1665-1671

3. Cao Y, Ma J (2011) Body mass index, prostate cancer-specific mortality, and biochemical recurrence: a systematic review and meta-analysis. Cancer Prev Res 4:486-501

4. Discacciati A et al (2011) Body mass index in early and middle-late adulthood and risk of localised, advanced and fatal prostate cancer: a population-based prospective study. Br J Cancer 105:1061-1068

5. MacInnis RJ, English DR (2006) Body size and composition and prostate cancer risk: systematic review and meta-regression analysis. Cancer Causes Control CCC 17:989-1003

6. Zuccolo L et al (2008) Height and prostate cancer risk: a large nested case-control study (ProtecT) and meta-analysis. Cancer Epidemiol Biomark Prev 17:2325-2336

7. Littman AJ, White E, Kristal AR (2007) Anthropometrics and prostate cancer risk. Am J Epidemiol 165:1271-1279

8. Freedland SJ, Platz EA (2007) Obesity and prostate cancer: making sense out of apparently conflicting data. Epidemiol Rev 29:88-97

9. Buschemeyer WC, Freedland SJ (2007) Obesity and prostate cancer: epidemiology and clinical implications. Eur Urol 52:331-343

10. Gong $\mathrm{Z}$ et al (2006) Obesity, diabetes, and risk of prostate cancer: results from the prostate cancer prevention trial. Cancer Epidemiol Biomark Prev 15:1977-1983

11. Collaboration Emerging Risk Factors (2012) Adult height and the risk of cause-specific death and vascular morbidity in 1 million people: individual participant meta-analysis. Int $\mathrm{J}$ Epidemiol 41:1419-1433

12. Epstein MM et al (2012) Dietary fatty acid intake and prostate cancer survival in Örebro County, Sweden. Am J Epidemiol 176:240-252

13. Rowlands M-A et al (2012) Circulating insulin-like growth factors and IGF-binding proteins in PSA-detected prostate cancer: the large case-control study ProtecT. Cancer Res 72:503-515

14. Rowlands M-A et al (2010) The relation between adiposity throughout the life course and variation in IGFs and IGFBPs: evidence from the ProtecT (Prostate testing for cancer and Treatment) study. Cancer Causes Control CCC 21:1829-1842

15. Lewis SJ et al (2010) Associations between an obesity related genetic variant (FTO rs9939609) and prostate cancer risk. PLoS One 5:e13485

16. Gunnell DJ, Smith GD, Frankel SJ, Kemp M, Peters TJ (1998) Socio-economic and dietary influences on leg length and trunk length in childhood: a reanalysis of the Carnegie (Boyd Orr) survey of diet and health in prewar Britain (1937-39). Paediatr Perinat Epidemiol 12(Suppl 1):96-113

17. Gunnell D et al (2001) Height, leg length, and cancer risk: a systematic review. Epidemiol Rev 23:313-342

18. Gunnell D (2002) Can adult anthropometry be used as a "biomarker" for prenatal and childhood exposures? Int J Epidemiol 31:390-394 
19. Davey Smith G, Ebrahim S (2003) Mendelian randomization: can genetic epidemiology contribute to understanding environmental determinants of disease? Int J Epidemiol 32:1-22

20. Davey Smith G, Hemani G (2014) Mendelian randomization: genetic anchors for causal inference in epidemiological studies. Hum Mol Genet 23:R89-R98

21. Palmer TM et al (2012) Using multiple genetic variants as instrumental variables for modifiable risk factors. Stat Methods Med Res 21:223-242

22. Burgess S, Thompson SG (2013) Use of allele scores as instrumental variables for Mendelian randomization. Int J Epidemiol 42:1134-1144

23. Lango Allen $\mathrm{H}$ et al (2010) Hundreds of variants clustered in genomic loci and biological pathways affect human height. Nature 467:832-838

24. Speliotes EK et al (2010) Association analyses of 249,796 individuals reveal 18 new loci associated with body mass index. Nat Genet 42:937-948

25. Kote-Jarai Z et al (2008) Multiple novel prostate cancer predisposition loci confirmed by an international study: the PRACTICAL Consortium. Cancer Epidemiol Biomark Prev 17:2052-2061

26. Eeles RA et al (2013) Identification of 23 new prostate cancer susceptibility loci using the iCOGS custom genotyping array. Nat Genet 45:385-391

27. Howie BN, Donnelly P, Marchini J (2009) A flexible and accurate genotype imputation method for the next generation of genome-wide association studies. PLoS Genet 5:e1000529

28. Lane JA et al (2010) Latest results from the UK trials evaluating prostate cancer screening and treatment: the CAP and ProtecT studies. Eur J Cancer 46:3095-3101

29. Burgess S (2014) Sample size and power calculations in Mendelian randomization with a single instrumental variable and a binary outcome. Int J Epidemiol 43:922-929

30. Collin SM et al (2008) Associations of lower urinary tract symptoms with prostate-specific antigen levels, and screen-detected localized and advanced prostate cancer: a case-control study nested within the UK population-based ProtecT (Prostate testing for cancer and Treatment) study. BJU Int 102:1400-1406

31. Didelez V, Sheehan N (2007) Mendelian randomization as an instrumental variable approach to causal inference. Stat Methods Med Res 16:309-330

32. VanderWeele TJ, Tchetgen Tchetgen EJ, Cornelis M, Kraft P (2014) Methodological challenges in Mendelian randomization. Epidemiology 25:427-435

33. Altman DG, Bland JM (2003) Statistics Notes: interaction revisited: the difference between two estimates. $\mathrm{Br}$ Med J 326:219

34. Evans DM et al (2013) Mining the human phenome using allelic scores that index biological intermediates. PLoS Genet 9:e1003919
35. Davey Smith G (2011) Use of genetic markers and gene-diet interactions for interrogating population-level causal influences of diet on health. Genes Nutr 6:27-43

36. Edwards TL, Giri A, Motley S, Duong W, Fowke JH (2013) Pleiotropy between genetic markers of obesity and risk of prostate cancer. Cancer Epidemiol Biomark Prev 22:1538-1546

37. Sutcliffe S, Colditz GA (2013) Prostate cancer: is it time to expand the research focus to early-life exposures? Nat Rev Cancer 13:208-518

38. Giovannucci E, Rimm EB, Stampfer MJ, Colditz GA, Willett WC (1997) Height, body weight, and risk of prostate cancer. Cancer Epidemiol Biomark Prev 6:557-563

39. Gunnell D et al (2004) Do height-related variations in insulin-like growth factors underlie the associations of stature with adult chronic disease? J Clin Endocrinol Metab 89:213-218

40. Calle EE, Rodriguez C, Walker-Thurmond K, Thun MJ (2003) Overweight, obesity, and mortality from cancer in a prospectively studied cohort of U.S. adults. N Engl J Med 348:1625-1638

41. Rodriguez C et al (2001) Body mass index, height, and prostate cancer mortality in two large cohorts of adult men in the United States. Cancer Epidemiol Biomark Prev 10:345-353

42. Freeman VL, Liao Y, Durazo-Arvizu R, Cooper RS (2001) Height and risk of fatal prostate cancer: findings from the National Health Interview Survey (1986 to 1994). Ann Epidemiol 11:22-27

43. Chen H, Miller BA, Giovannucci E, Hayes RB (2003) Height and the survival of prostate cancer patients. Cancer Epidemiol Biomark Prev 12:215-218

44. Rowlands M-A et al (2012) Serum insulin-like growth factors and mortality in localised and advanced clinically detected prostate cancer. Cancer Causes Control CCC 23:347-354

45. Würtz $P$ et al (2013) Lipoprotein subclass profiling reveals pleiotropy in the genetic variants of lipid risk factors for coronary heart disease: a note on Mendelian randomization studies. J Am Coll Cardiol 62:1906-1908

46. Nelson CP et al (2015) Genetically determined height and coronary artery disease. N Engl J Med 372:1608-1618

47. von Hinke Kessler Scholder S, Davey Smith G, Lawlor DA, Propper C, Windmeijer F (2012) The effect of fat mass on educational attainment: examining the sensitivity to different identification strategies. Econ Hum Biol 10:405-418

48. von Hinke Kessler Scholder S, Davey Smith G, Lawlor DA, Propper C, Windmeijer F (2013) Child height, health and human capital: evidence using genetic markers. Eur Econ Rev 57:1-22

49. Nordestgaard BG et al (2012) The effect of elevated body mass index on ischemic heart disease risk: causal estimates from a Mendelian randomisation approach. PLoS Med 9:e1001212

50. Fowke JH, Motley S, Dai Q, Concepcion R, Barocas DA (2013) Association between biomarkers of obesity and risk of high-grade prostatic intraepithelial neoplasia and prostate cancer-evidence of effect modification by prostate size. Cancer Lett 328:345-352 